\title{
La figura del xilógrafo en las revistas ilustradas del siglo XIX
}

\author{
M. ${ }^{\text {a }}$ Dolores Bastida de la Calle*
}

\begin{abstract}
RESUMEN
Hubo un cierto intervalo de tiempo en el siglo xIX, de 1840 a 1880 aproximadamente, en el que las condiciones técnicas y sociales

propiciaron la aparición y el mantenimiento de un "arte menor", que involucró a dibujantes y grabadores: la ilustración de noticias en revistas de actualidad. En el articulo se pretende estudiar como la impresión barata y rápida de imágenes, tal como exigia este tipo de revistas, sólo se hizo posible mediante la técnica de xilografia a la testa, sobre duros tacos de boj cortado a contrafibra. Se enfatiza, por otra parte, la importancia del papel del xilógrafo en la estampa, y se estudia su trayectoria protesional, desde la singularidad de Thomas Bewick hasta la aparición del taller artesanal de los grandes semanarios, con su particular distribución del trabajo y variedad de instrumentos de grabación. Se señala, asimismo, como la

\section{ABSTRACT}

There was certain period of time in the $x I x$ century, from about 1840 to 1880 , when social and technical conditions led to the flourishing of a minor art that involved illustrators as well as engravers: picturing news in graphic magazines. This paper briefly examines how the cheap and fast printing of both pictures and type, as required by popular magazines, was only made possible through the relief wood engraving process, which used hard woodbox blocks cut across the grain. The paper further emphasizes the role played by the xylographer in the graphic press, and studies his professional evolution, from the work of Thomas Bewick until the appearance of engraving workshops at the newsweeklies, with their particular way of assigning tasks, and their variety of tools to carve the wood. It is also shown that the print linear system
\end{abstract}

* Dpto. de Historia del Arte. UNED. 
estructura lineal de la estampa variaba de un pais a otro, y se subraya la impronta del grabador en el acabado de la obra, lo que a veces hacía dificil distinguir estampas de diferentes dibujantes dentro de una misma revista. varied among countries, and that the mark left by the engraver in the final illustration was such as to often make difficult distinguishing between different illustrators within the same magazine.

Toda la prensa ilustrada del siglo XIX, sea el Magazine de los años 30 y sus posteriores variantes, sea la revista ilustrada de actualidad, debe su existencia al grabado en madera. Existió pues una conexión cercana, casi familiar, entre el grabado en madera y la información gráfica. El desarrollo de la xilografia a la testa 0 a contrafibra durante el primer cuarto del siglo XIX proporcionó las condiciones técnicas en base a las cuales el periodismo ilustrado iba a desarrollarse. Una popular cultura visual emergió de las imágenes. Los grabados de revistas revelaban las últimas tendencias sociales, los acontecimientos del momento, las actitudes, las ideas, el escenario de un país. En el editorial que acompañaba a su primer número, el 14 de mayo de 1842, la revista inglesa The Illustrated London News, pionera en la ilustración gráfica de actualidad, recordaba cómo el arte gráfico había "convertido los bloques (del xilógrafo) en sabiduría, y dado alas y espíritu a la madera inerte y sin vida».

Antes de la aparición de la obra de Thomas Bewick, a finales del siglo XVIII, la xilografía había quedado reducida a la impresión de etiquetas, almanaques, viñetas tipográficas. Bewick, a quien se debe su revival, está así directamente involucrado en la creación de la prensa ilustrada. Existen antecedentes en el mismo siglo XVIII a la introducción de la nueva técnica por Bewick. El xilógrafo francés J.B. Michael Papillon, en su Traité de la Gravure en bois, publicado de 1751 a 1776, habla de un grabador extranjero, "el extravagante", de paso por París antes de 1768, quien trabajaba el boj con el buril ${ }^{1}$. Pero Papillón no puede referirse a Bewick, quien aparentemente no salió jamás de Inglaterra. El personaje misterioso podría haber llegado de Oriente. En París se conocian una serie de grabados sobre madera de boj, muy anteriores a los de Bewick, impresos por armenios en 1709, en Constantinopla, en el Libro de Historia o Agathangelos; la obra, con ilustraciones de estilo pseudo-persa, contiene tres estampas fuera de texto y dos composiciones decorativas. Asimismo, Foy de Lyon, grabador del Correo Regio del Reino en Paris, parece haber practicado el

Gsuman, Pierre, La Gravure sur bois en France au xix siècle. París, Albert Morancé, 1929, págs. 9 y 10 . 
nuevo método hacia 1760 , sin haber sacado consecuencia práctica alguna. Por otra parte, un xilógrafo gallego, Enrique Mayer, descubrió en Santiago de Compostela pequeñas planchas de boj a la testa, grabadas con temas decorativos y utilizadas hacia 1750 para imprimir las orlas de los títulos o diplomas universitarios sobre piezas de raso o seda, del color correspondiente a cada facultad ${ }^{2}$. Finalmente, Jacob Kainen ha demostrado que la contrafibra había ya alcanzado un cierto desarrollo en la misma Inglaterra del siglo XVIII.

Pero si bien la técnica a la testa estaba en uso antes de Bewick, sólo el grabador inglés, nacido en las cercanias de Newcastle en 1753, dejó una obra duradera. El aplicó los principios con un sentido práctico y abrió así al grabado en madera un grado de dignidad que antes nunca habia conseguido, y un porvenir que él mismo, de hecho, acertó a predecir. Ruskin dijo de él: "sin haber tenido maestros en xilografía, está a la altura de Holbein" y también "desde el siglo XVI, salvo el caso de Holbein y Turner, no hay dibujo tan sutil como el de Bewick ${ }^{3}$.

Durante largo tiempo el dibujante había estado a merced del grabador, que estaba más interesado en demostrar su propia habilidad que en traducir cuidadosamente las líneas. Bewick, sin embargo, combinó ambas profesiones y grabó, con maestría de la que era consciente (en algunos de sus grabados y tras su firma, uno puede encontrar juntas las abreviaturas "del « y "sculp"), sus propios dibujos, la mayor parte de los cuales fueron inspirados por un amplio conocimiento de la vida del campo y la historia natural. En 1767 entró a trabajar con Ralph Beilly, un calcógrafo de Newcastle, pero en el curso de siete años de aprendizaje tuvo ocasión de descubrir que el boj a contrafibra, menos duro que el metal, podia, no obstante, ser tratado con el buril (fig. 1). El moderno grabado en madera se perfila así como enraizado en la técnica calcográfica y no en la antigua xilografía.

Algunos de entre sus muchos discípulos se trasladaron a Londres, donde establecieron talleres de carácter crecientemente industrial: su hermano John, Charles Nesbit, William Harvey, quienes mantuvieron, sin embargo, una fuerte conexión con el grupo matriz de Newcastle. Por el contrario, Robert Branston, jefe de uno de los principales talleres londinenses, adquirió su destreza, como Bewick, trabajando el cobre con su

Garcia Minoh, A., Xilografia y xilógrafos de ayer y de hoy. Oviedo, Diputación de Asturias e Instituto de Estudios Asturianos (C.S.I.C.), 1975, pág. 30

Austin. Stanley. The History of Engraving. From its inception to the time of Thomas Bewick. Londres, Werner Laurie (impresor), s. a. pág. 175 


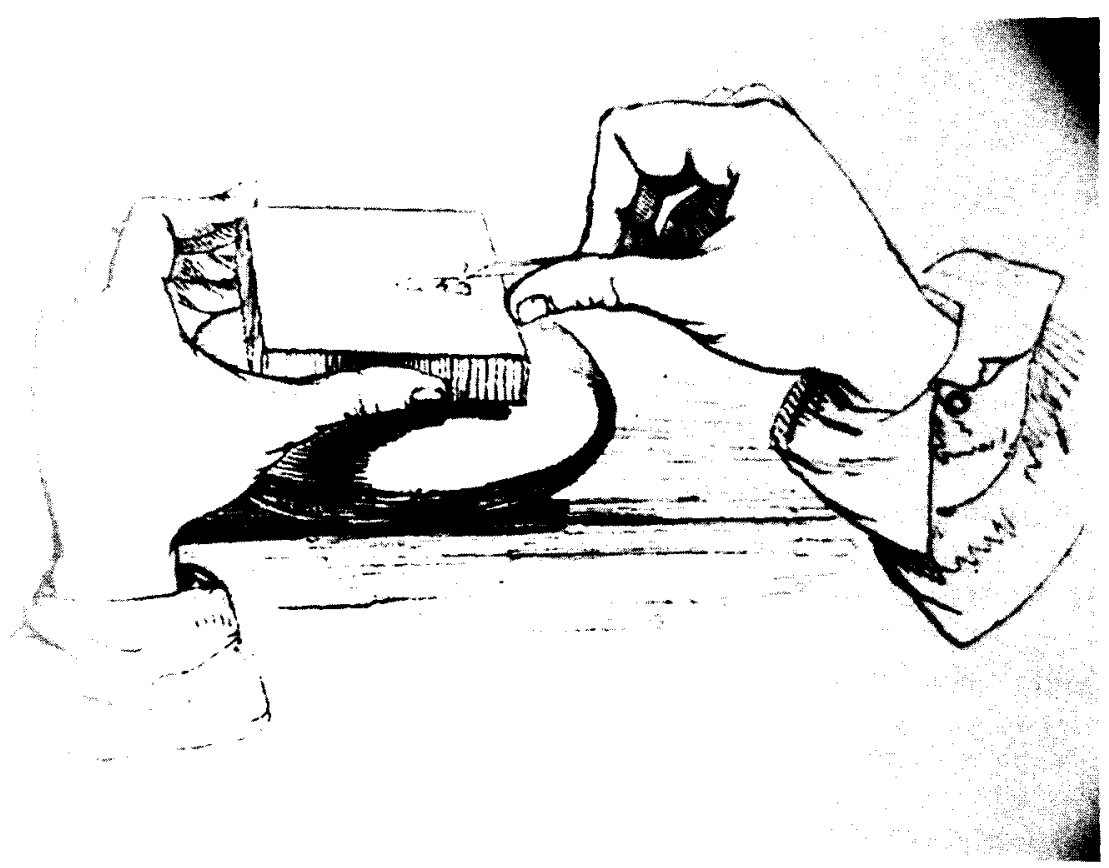

Fig. 1. Posición de las manos para grabar, con la tabla apoyada sobre un cojín de arena para poder variar fácilmente su inclinación.

padre. En el taller de Branston se formó Charles Thomson, el grabador que, llamado a París en 1817, ayudó a consolidar la manera inglesa en Francia; los concursos que, en un intento de fomentarla, organizó la "Societé d'Encouragement pour l'Industrie Nationale» en 1805, 1808 y 1810 , no habían tenido éxito alguno. Alemania, cuna del antiguo grabado en madera, recibió también un cierto número de xilógrafos llegados de Inglaterra: a mediados de siglo había hasta 22 ingleses grabando a la testa en Leipzig, la ciudad que vio nacer al Illustrirte Zeitung. En Estados Unidos, fue un americano, Alexander Anderson, quien introdujo el grabado al boj. Anderson se limitó, sin embargo, a reproducir las estampas originales inglesas, y fueron emigrantes británicos, como W.J. Linton y Timothy Cole, quienes decidieron finalmente el curso del nuevo arte en América. En España, la irradiación de la técnica de Bewick no tuvo el arraigo temprano de la litografía. No fue hasta mediados los años treinta cuando, por influencia francesa, se inició el grabado a la testa en nuestro país. En la lentitud de la reacción española pudo haber influido el retraso del pais en actividad comercial e industrial, fundamental para la xilografía. 
El árbol usado casi exclusivamente para este propósito, el boj, tiene una madera de color claro, veta apretada y dureza próxima a la de la piedra, que puede cortarse con gran precisión. Aunque el boj crece lentamente, y el tronco raramente alcanza los 20 centímetros de diámetro, su comercio y consumo en la producción de ilustraciones de revista alcanzó en la segunda mitad del siglo un volumen ingente.

Con preferencia se utilizó la variedad turca, extendida por el Cáucaso en bosques que se adentran centenares de kilómetros desde las costas de los mares Negro y Caspio. Una vez talados, los troncos eran acarreados por caballos hasta el río más cercano, por donde bajaban a un puerto de embarque. Los ejemplares seleccionados para la preparación de matrices eran cortados transversalmente en piezas rectangulares de dos o tres centímetros de grosor, desechando las partes externas y la corteza. Las piezas o tacos se apilaban después en almacenes calentados gradualmente; aunque la duración media de este proceso de curación era de cuatro o cinco años, las necesidades comerciales rara vez permitían cumplir ese plazo ${ }^{4}$.

Debido a lo menudo del tronco, los tacos de boj solían tener lados de cinco a siete centímetros, y era necesario unir muchos para obtener planchas o bloques del tamaño adecuado a las exigencias de una revista ilustrada. En la época de los Magazines, los tacos se unían con pegamento, o bien por medio de tornillos fijos que pasaban a través de todo el bloque. Una vez trazado el dibujo en tinta china sobre una fina capa de blanco de España, extendida como fondo sobre la superficie de la plancha ${ }^{5}$, la última etapa era la talla xilográfica.

Un grabador podía emplear hasta tres semanas en una página completa de la revista. Esto era demasiado tiempo para la natural urgencia de la ilustración de noticias y, mediado el siglo, se introdujo una innovación. El éxito de un semanario ilustrado de actualidad descansaba en una detallada división del trabajo. Había un director que dominaba todos los aspectos de la publicación (cuestiones administrativas, decisiones sobre arte, procedimientos mecánicos para su producción), un cuerpo de redactores para las distintas áreas, y un equipo de dibujantes. Cuando se recibía información de que algo había ocurrido, o iba a ocurrir, se enviaba inmediatamente al punto de interés a uno o más artistas capaces de recoger es-

\footnotetext{
4 JACKSON, Mason, The Pictorial Press : lts origins and progress. Londres, Hurst and Blackett, 1885, pág. 316.

5 COLE. Alphaeus P. and WARD, Margaret, Timothy Cole, Woodengraver. Nueva York, The Pioneer Associates, 1935.
} 


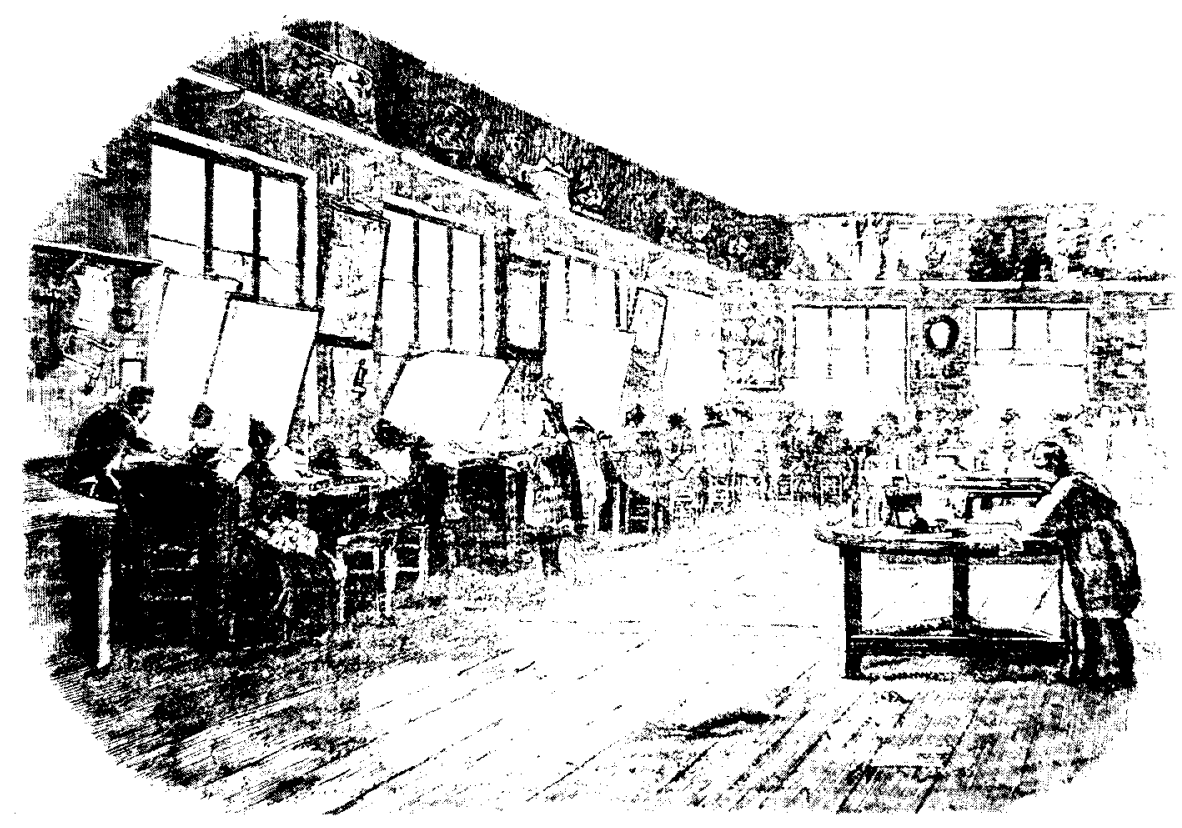

Fig. 2. Taller de grabadores del Frank Leslie's Illustrated Newspaper en 1856.

cenas rápidas en apuntes, tomados a lápiz y completados más tarde sobre el papel o directamente en el bloque, bien por ellos mismos, bien por dibujantes de estudio. Para reducir el tiempo consumido en la talla de estampas urgentes, las revistas, especialmente las inglesas, pasaron ahora a organizar cuerpos de grabadores (fig. 2).

Los tacos (unos quince a página completa, y el doble para una ilustración a doble página) se unían mediante tornillos y tuercas, con lo cual resultaba una plancha desmontable (fig. 3). Trazado el dibujo sobre ésta, se podían repartir sus piezas entre una docena de grabadores que trabajaban como especialistas en figuras, fondos y otros detalles, "siguiendo los complicados contornos de las ilustraciones con una pasmosa seguridad y destreza y al mismo tiempo un toque artístico" ${ }^{6}$. Para ayudar a la consecución de un rayado sutil, se utilizaban buriles con una variedad de grosores y formas, hasta un total de nueve. Para líneas de grosor variable se usaba una sección romboidal (fig. 4), en el caso de rectas, y una sección

Véase Frank Leslie's IIIustrated Newspaper, “How Illustrated Newspapers are made», agosto $2,(1856)$, pag. 124 . 


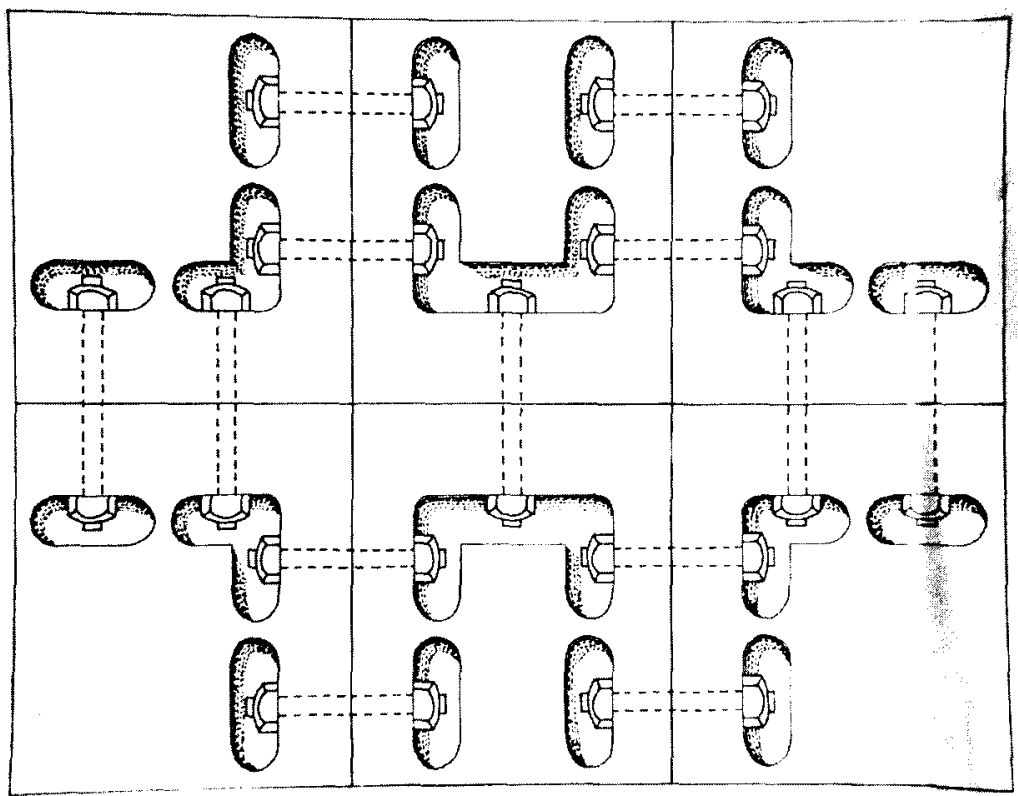

Fig. 3. Plancha de madera desmontable.

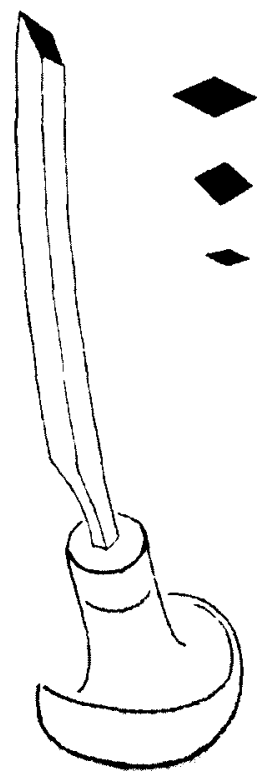

Fig. 4. Buril de sección romboidal o buril tipo. 
curvada ("uñeta») en el caso de líneas curvas ${ }^{7}$. Los trazos de grosor unjforme se obtenían con buriles de sección triangular muy fina, o con el buril rayado (de punta múltiple). Las grandes superficies blancas se dejaban a aprendices que las rebajaban con la gubia, o con el buril chaple, que se diferencia de la anterior en que la sección en forma de U mayúscula está llena. La gran dificultad de la tarea era, sin embargo, la prisa. Se trabajaba día y noche, y ocasionalmente dibujante y grabador lo hicieron simultáneamente. M. Jackson ${ }^{8}$ cuenta que hubo casos en los que el ilustrador no llegó a ver su dibujo completo. Un xilógrafo supervisor indicaba en los bordes de los tacos la dirección general de las líneas a seguir, y cada grabador completaba su trabajo, guardando en lo posible un estilo uniforme.

Por otra parte, no fue raro que el xilógrafo trabajase sobre un dibujo realizado a partir de una fotografía ${ }^{9}$. En ocasiones el punto de partida fue la misma foto, en cuyo caso fue necesario traducir las grandes áreas de claro-oscuro a algún equivalente en términos de líneas y puntos. Otras veces el punto de partida fue el negativo mismo de la fotografía que se colocaba sobre la plancha de madera previamente sensibilizada a la luz ${ }^{10}$, traduciendo a continuación el grabador la estructura tonal a una estructura lineal. Este procedimiento se denomina fotoxilografía.

Sin embargo, la técnica fotográfica influyó tempranamente en un segundo aspecto de la xilografía. En los años cincuenta, tras variados ensayos, se estableció un procedimiento para transferir al bloque de boj, fotográficamente, un dibujo trazado en un papel. Aunque los primeros intentos, realizados en The Mirror $y$ The Magazine of Sciences, datan de 1839, se puede atribuir a Robert Langton la consolidación de un método definitivo, en 1854, en la revista Art Journal ${ }^{11}$. El método, no obstante, tardaría un tiempo en hacerse de uso general.

La madera se empapaba en una solución de sal común, se secaba, y se empapaba de nuevo en otra solución de nitrato de plata que formaba una capa de cloruro de plata sensible a la luz. El procedimiento presentaba múltiples ventajas. Producía sobre la plancha, rápida y exactamente, una imagen invertida del dibujo, condición necesaria para obtener en cada

Blggs, John R., Classic Woodcut Art and Engraving. Londres. Blandford Press, 1989, pág. 46.

JACKSON, M., Op. cit., págs. 320 y 321.

IVINS, William M., How Prints Look. Boston, Beacon Press, 1987, pág. 37.

Gascolgne, Bamber, How to Identify Prints. Londres, Thames and Hudson, 1986, pág. 6.

WAKEMAN, Geoffrey, XIX Century Illustration, some methods used in English books, illus trated with original examples of the processes. Loghborough (Inglaterra), The Plough Press, 1970. pág. 76 . 
copia la imagen original. Eliminaba toda restricción sobre el tamaño de una ilustración porque las fotografías podían ser ampliadas o reducidas para adaptarlas al bloque de madera. Finalmente, en unos casos liberaba al artista de la necesidad de dibujar sobre la madera; y en otros, al evitar el calco, hacía posible la conservación del original, que podía quedar a disposición de su autor.

Los grabadores, no obstante, reaccionaron de modo diverso ante la nueva técnica. W.L. Thomas, el primer director del Graphic, hizo un uso sistemático del procedimiento ${ }^{12}$, y los hermanos Dalziel sostuvieron que era ventajoso disponer de un criginal intacto que sirviese como una guía independiente para el xilógrafo. W. J. Linton ${ }^{13}$, sin embargo, señalaba en 1884 , ya resignado al procedimiento, que éste hacia muy desagradable el trabajo de la talla, pues la vista sufría en la repetida acomodación, al mirar de la plancha al original y de nuevo a la plancha. En La Ilustración Española y Americana del 8 de mayo de 1875, se lee: «... los interesantes dibujos... tomados del natural, y trasladados con todos sus detalles a la madera por medio de procedimientos fotográficos" ${ }^{14}$.

Ciertamente el sistema lineal de grabación dependia en gran manera del taller xilográfico. El grabador podía añadir un cierto encanto al dibujo, al que solía ser fiel, sin embargo, para no desvirtuar la obra del ilustrador. En una exposición de sketches de "reporteros gráficos de guerra" celebrada en Londres, en el Palacio de Cristal, en 1870, el catálogo de la época hacia un comentario sobre la naturaleza de la ilustración de tema bélico: "Un examen de estos sketches nos convence de que un periódico con buenos grabadores e inferiores artistas, producia mejores y más exactas imágenes que otro cuyos artistas sean excelentes, pero cuyos grabadores sólo puedan copiar lo que esté ante ellos" ${ }^{15}$. Se ha pensado que, de hecho, el xilógrafo controlaba totalmente la obra terminada, y que su intervención eliminó los rasgos originales de cada dibujante, de modo que sólo es posible distinguir entre iiustraciones de distintos países, o quizás de distintas revistas

Existen, en particular, diferencias apreciable; entre las técnicas usuales en las revistas francesas e inglesas. En las primeras, para sugerir sombras y volúmenes, se solia utilizar un rayado continuo y uniforme (fig. 5); en las segundas se usaba un entramado. En The Illustrated Lodon News, ese

Trumpt James, English Ilustration. The Nineties. Londres, Faber and Faber, 1935, pág. 6. Matil. Eric de. The Victorian Wood Block Illustrators. Londres, Gordon Fraser, 1980, pág. 52. La llustración Española y Americana. mayo 8. (1875). pág. 283.

Hongson, Pat, The War Ilustrators. New York, Macmillan, 1977, pág. 31 


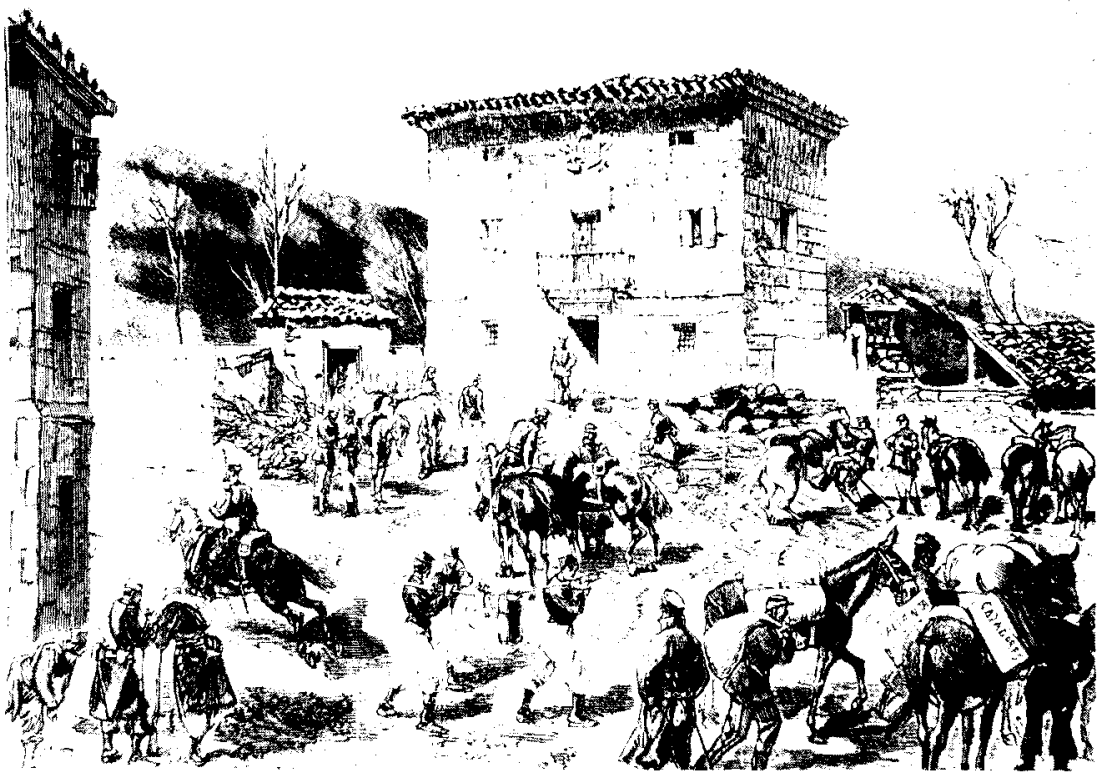

Fig. 5. Le Monde lliustré, 4 de abril de 1874.

entramado era a menudo irregular, y el grabador tendía a dejar grandes zonas en blanco, en un claro-oscuro muy simple (fig. 6).

Las revistas francesas siempre reconocian explicitamente la importancia de sus grabadores, mostrando su nombre en una esquina de la estampa, acompañado de "SC" (del latín sculpit). En Le Monde Illustré destaca la obra de grabadores como Fortuné-Louis Méaulle, Alphonse Tauxier, y Louis JosephAmédée Daudenarde, y en L'Illustration muchas de las estampas fueron talladas por Smeeton-Tilly, dos grabadores asociados durante largo tiempo, cuya firma se hizo frecuente en otras muchas publicaciones gráficas de la época. Smeeton, un ingles instalado en Paris en 1840, estuvo muy ligado a círculos frecuentados por ilustradores y xilógrafos y terminó colaborando con Augusto Tilly, un artista al que, por otra parte, el Magassin Pittoresque debe magníficos grabados. Hay, también, ejemplos de firmas asociadas en estampas de La Nuova Illustrazione Italiana, caso de Barberis-Canedi (agosto 2, 1874) y Canedi-Centenari (octubre 25,1874 ). Aqui, sin embargo, se da una asociación de grabador y dibujante, en una labor complementaria, de dibujo y talla en la madera. François Canedi fue un xilográfo, natural de Milán, que se estableció finalmente en Lyón, en cuyo Salón expuso después de 1889; Centenari, nacido en Parma en 1841, fue pintor de género y restaurador. 


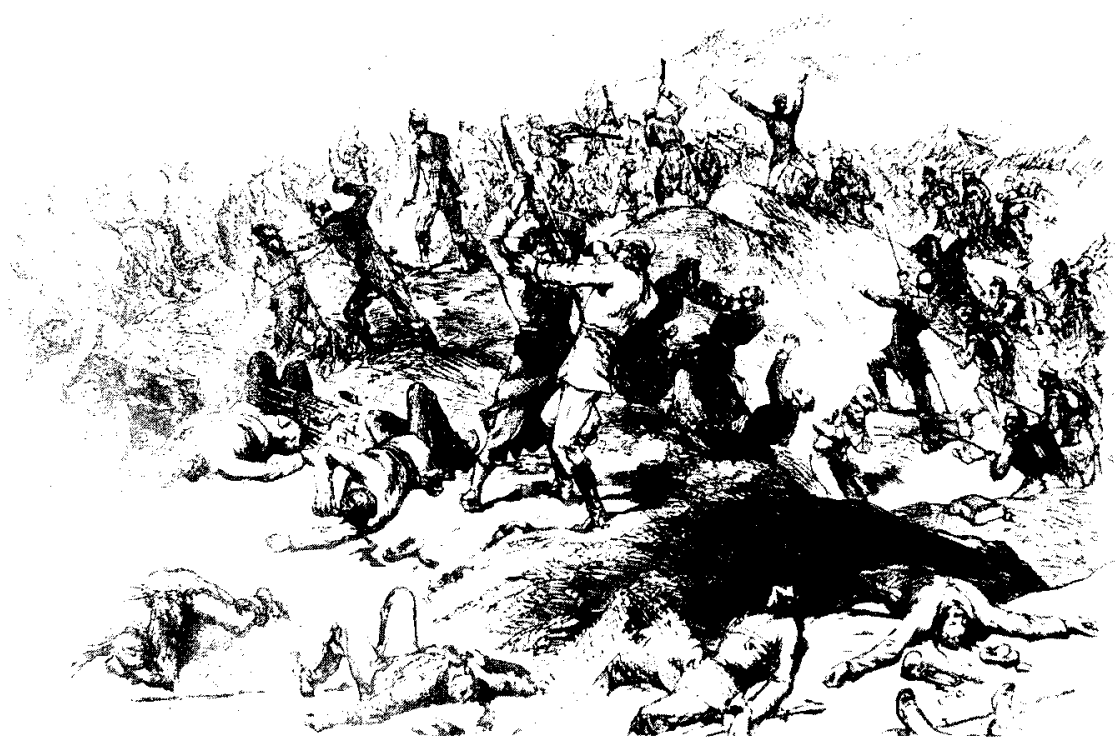

Fig. 6. The Illustrated London News. 5 de septiembre de 1874

Por el contrario, al igual que con los dibujantes de estudio, las revistas inglesas ignoran usualmente el papel del grabador en la ilustración; en los grandes talleres de grabación británicos, en las que cada artista, casi un artesano, era especialista en una materia, era infrecuente individualizar la obra de un xilográfo particular. En los escasos ejemplos en los que aparece una firma completa seguida del "SC" se trata de artistas con identidad propia, como Crane, W.J. Palmer y. sobre todo, H. Harral.

En las revistas alemanas como el Illustrirte Zeitung, siguiendo la costumbre inglesa, no se hace referencia, por lo general, al nombre del grabador. La influencia británica fue intensa en Leipzig, sede del semanario alemán, donde trabajaban, mediado el siglo, un alto número de grabadores ingleses. En contraste con la xilografía alemana tradicional, que rehuía el vacio pictórico y llenaba toda la estampa, muchos de los grabados del Illustrirte Zeitung no presentan, usualmente, un acabado muy completo en detalles exactos, que ahora resultaba poco sugestivo y que, por otra parte, no podía competir con la fotografía.

En las revistas rusas como la Vserminaia Illiustratsia, muchas de las estampas son reproducciones de los semanarios de Paris y Londres. En la mayoría de los casos es posible afirmar que el procedimiento de copia fue 
la producción de una nueva matriz: un xilográfo en San Petersburgo seguía, en lo posible, la misma red de líneas de la estampa copiada. Por ejemplo, en un grabado ruso del 24 de marzo de 1873 (fig. 7), no figuran las iniciales J.N. de la ilustración original inglesa (fig. 8) del Graphic del 22 de febrero de 1873, mientras que en la leyenda, por el contrario, se hace referencia al nuevo grabador, A. Dauguel. A veces, de hecho, el nombre del grabador local (Dauguel, May, Danmuller) aparece dentro de la "nueva» estampa. En ésta, sin embargo, se aprecia usualmente cierta falta de realismo y vigor plástico en las figuras, debido a un sombreado ligeramente menos sutil que impide alcanzar una completa sensación de volumen (véase fig. 8). Por otra parte, el seminario de San Petersburgo también usó a veces el procedimiento del cliché, esto es, un duplicado de la matriz original.

En La llustración Española y Americana sobresalen las obras de Tomás Carlos Capúz y Bernardo Rico. Un examen de las estampas muestra que, tanto uno como otro, grabaron directamente muchos de los croquis recibidos en la redacción, sin mediación de artista de estudio. Rico, por otra parte, actuó en algún caso de reportero gráfico; así, el 16 de septiembre de 1873 el semanario decia textualmente: "Nuestro director artístico, el Sr. D. Bernardo Rico, salió para el lugar del siniestro con objeto de tomar apuntes d'après nature". El equipo de La Ilustración Española y Americana incluía otros muchos conocidos xilógrafos de la época, como Carretero, Paris, Severini, Manchon, Marichal. Es curioso observar que la mayor parte de los retratos de personajes, en su mayoría sacados de totografias, fueron realizados por Paris.

En la etapa de impresión que seguía al grabado, la tonalidad de la estampa se podía ver afectada por una diversidad de procedimientos. Cuando el grabador quería conseguir un efecto delicado en alguna parte del dibujo, raspaba esa área para que en la estampación sufriese menos presión que otras partes vecinas, y en consecuencia quedara más clara. Una técnica era tomar una primera impresión en papel muy grueso, retirar las partes blancas de la imagen con un instrumento afilado, en un proceso lento y cuidadoso, y a continuación fijar la estampa asi recortada sobre el tímpano de la prensa. De esta forma, en sucesivas copias. se producia un exceso de presión en ciertas partes del grabado, y se podian obtener efectos brillantes de tonalidad. A veces, sin embargo, lo que se aprecia son defectos en el entintado, tales como la aparición de líneas blancas verticales como consecuencia del mal encaje de los tacos en el bloque (fig. 9).

El trabajo del grabador se encuentra en la frontera entre técnica y forma artística. En los manuales de ilustración gráfica, la obra de Bewick, por 


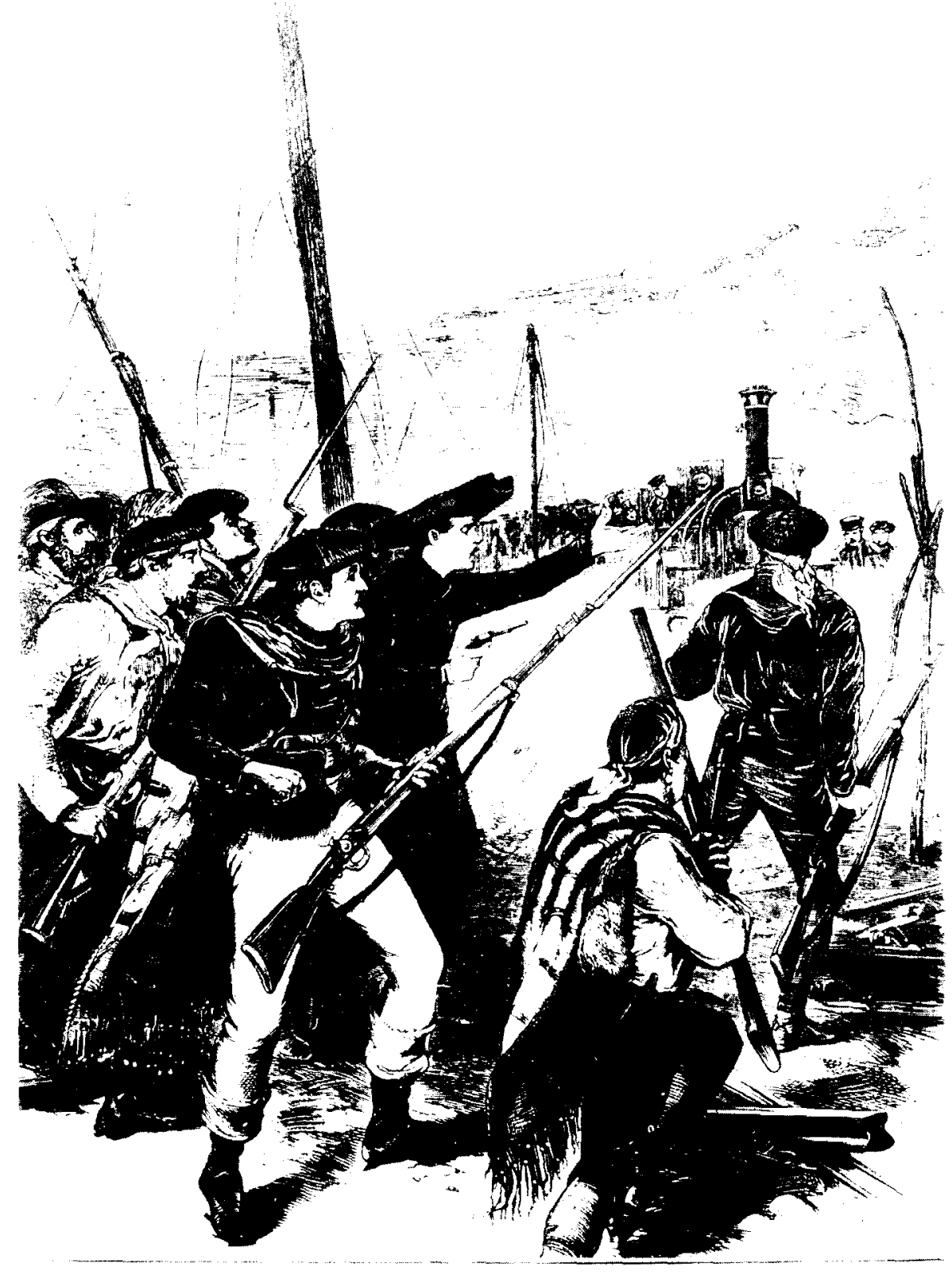

Fig. 7. Vsemirnaia Illiustratsiia, 24 de marzo de 1873. 


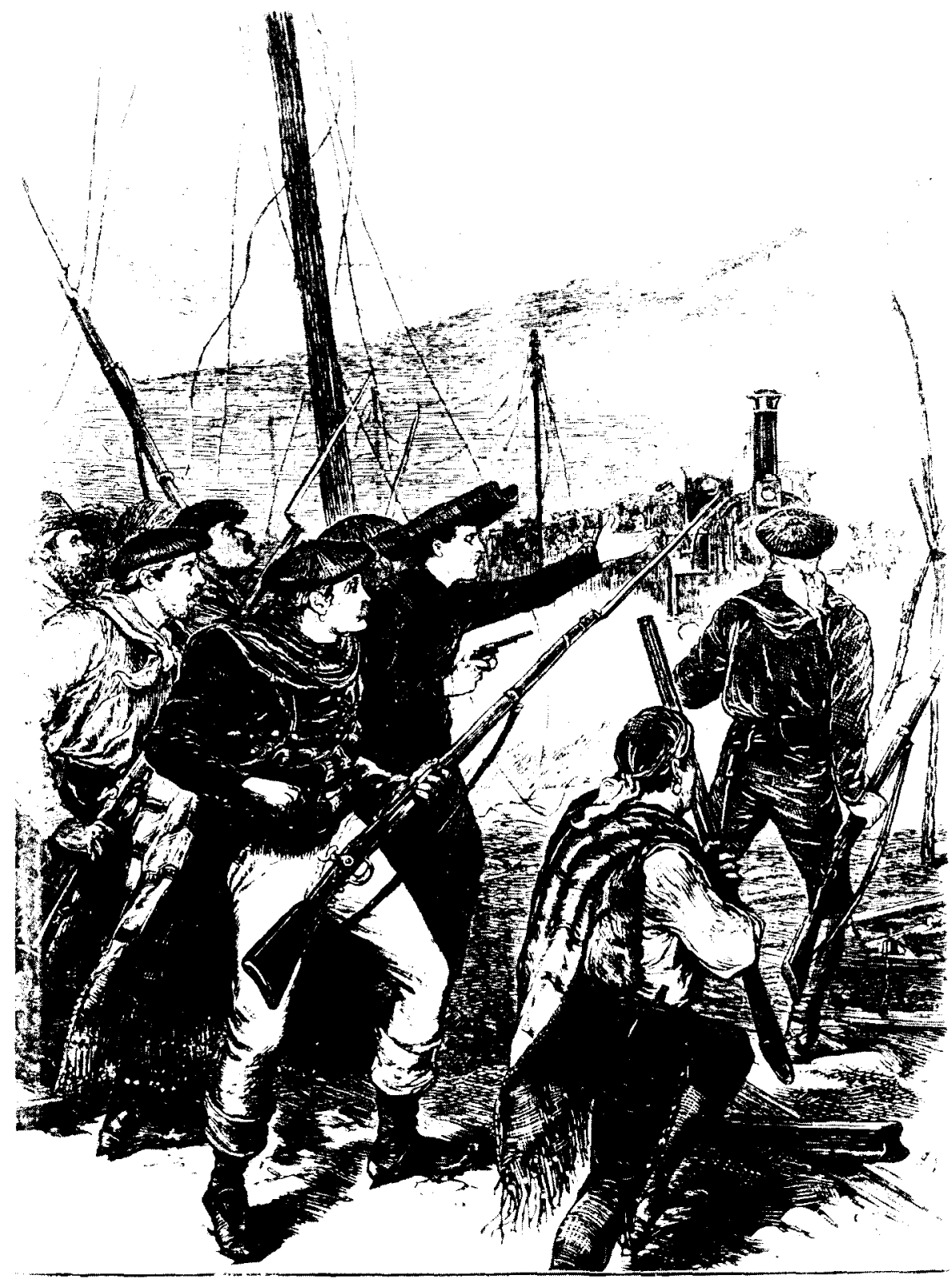

Fig. 8. The Graphic, 22 de febrero de 1873 

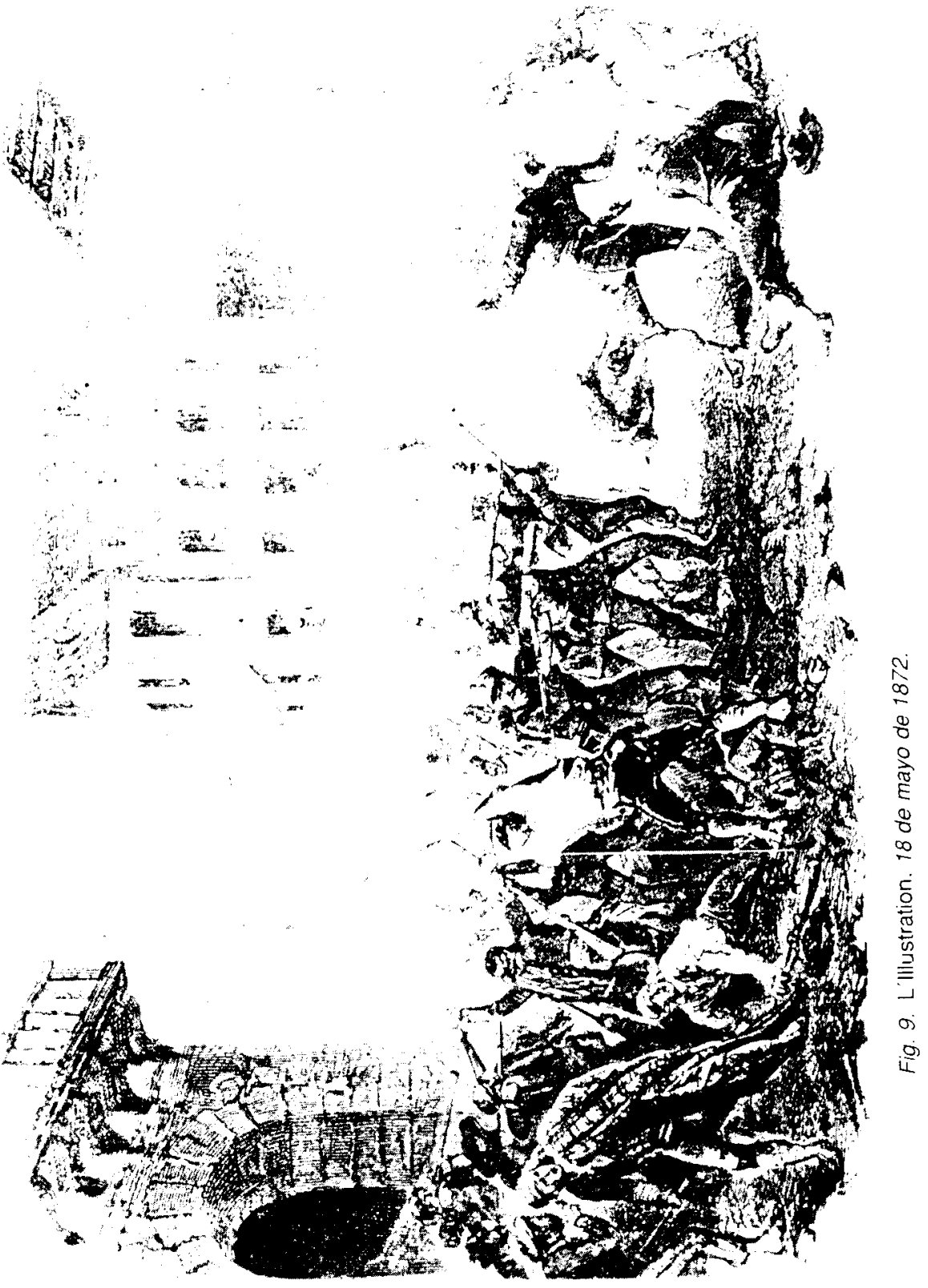
ejemplo, aparece ampliamente tratada, pero apenas se la menciona en libros dedicados al grabado, y es omitida enteramente en los de Historia del Arte. Charles Rosen y Henry Zerner han subrayado que esta posición de la crítica está relacionada con el hecho de que el grabador inglés quiso ser un artesano alejado del mundo artístico; pero también con la jerarquía de géneros y valores enraizados en el historiador del arte, quien se resiste a apreciar una labor artesanal.

Esta labor de interpretar la concepción del artista mediante cortes sobre la madera, se consideró también en el siglo XIX como una tarea adecuada para el trabajo artístico de la mujer. El hecho de que hacia mediados de siglo se "animase" a las mujeres a buscar empleo en el campo del grabado comercial, lo confirma la creación de un curso para enseñar la práctica xilográfica a contrafibra en la Female School of Art, creada en Londres en 1842. En 1849 había en la clase nueve estudiantes, que dedicaban dos días a la semana a la práctica del grabado y los tres restantes al dibujo. Pero la idea de incluir este tipo de empleo dentro de los roles de trabajo femenino, incorporaba, evidentemente, un fuerte elemento del contemporáneo concepto sobre la inferioridad de la mente de la mujer, concepto que consideraba adecuado para ella lo manual y lo repetitivo, pero no lo creativo. Muchas de estas mujeres encontraron empleo en el staff de grabadores de las publicaciones ilustradas, como, por ejemplo, en el del Illustrated London News.

Con respecto a este semanario, el Art Journal señalaba en 1872: “Con anterioridad hubo mujeres empleadas en el equipo de grabadores del Illustrated London News. Ahora no hay ninguna trabajando alli, y es difícil oir algo sobre ellas en algún sitio, aunque sabemos que el grabado en madera se sigue usando mucho" ${ }^{16}$. Mujeres artistas de las que se sabe realizaron este trabajo fueron, entre otras. Adelaide Claixton, que grabó para el Illustrated Time y el London Society, Lucy Faulkner y Jean Morris, que grabaron para William Morris, y la americana Alice Stephens, elegida por Thomas Eakins para reproducir sus pinturas. 